EPiC Series in Engineering
Volume 3, 2018, Pages 2433-2440
HIC 2018. 13th International
Conference on Hydroinformatics

\title{
China National Flash Flood Disasters Investigation and Assessment
}

\author{
Xiaolei Zhang ${ }^{1,2 *}$, Liang Guo ${ }^{1,2}$, Ronghua Liu ${ }^{1,2 \dagger}$, Qi Liu ${ }^{1,2}$, Qiuling Yao ${ }^{1,2}$, \\ Yesen Liu $^{3}$, Huili Zhang ${ }^{1,2}$, Yali Wang ${ }^{1,2}$, Rong Zhou \\ ${ }^{1}$ China Institute of Water Resources and Hydropower Research, Beijing 100038, China \\ ${ }^{2}$ Research Center on Flood \& Drought Disaster Reduction of the Ministry of Water Resources, \\ Beijing 100038, China \\ ${ }^{3}$ State Key Laboratory of Hydraulic Engineering Simulation and Safety, Tianjin University, \\ Tianjin 300072, China \\ ${ }^{4}$ China Renewable Energy Engineering Institute, Beijing 100120, China
}

liurh@iwhr.com

\begin{abstract}
National Flash Flood Disasters Investigation and Assessment project is the largest non-engineering projects in water conservancy industry in China, and also the largest scale of general census on disasters' background in flood management and mitigation fields. Through general census, on-site investigation, field measurement, hydrological analysis and calculation, the spatial distribution, human settlement, underground situations, social and economic impacts, hazard zoning, warning indicators of flash flood disasters were collected, the storm flood characters in mountainous areas were analyzed, the flood control ability of selected villages were assessed, the critical rainfall index of these villages were obtained, and the hazard zones were finally identified, all of which provided a strong information support for flash flood early-warning and forecast and residential safety transfer. This paper systematically introduced the key technical focuses, made a general review on the data and information collected, and discussed the spatial distribution pattern of these elements. Based on these survey data, the characteristics of flash flood disaster prevention areas, the human settlement features and storm flood spatial distribution situation were further analyzed. In the end of this paper, future application and analysis on diversified utilization of national flash flood disasters investigation and assessment results were proposed.
\end{abstract}

\footnotetext{
${ }^{*}$ This paper is supported by China National Flash Flood Prevention Project (No. 1261430112030, 1261530180074, 126301001000150068) and IWHR grant (No. JZ0145C022017).

${ }^{\dagger}$ Corresponding author: Ronghua Liu, senior engineer, IWHR, research field flood forecasting and warning, hydroinformatics.
} 


\section{Introduction}

Flash flood disasters are characterized by their massive destruction, their unexpectedness and the substantial losses caused by them. Flash flood disasters often cause casualties, house collapse, flooded towns, infrastructure damage, change in fluvial morphology and destruction of natural environment (Keefer, 1987). China suffers a wide range of flash flood disasters. It ranks among the top in the activity intensity and outbreak scale of flash flood disasters and in the economic losses and casualties caused by them (Shang Q M, 2007). According to statistics, China's death toll of flash flood disasters in 2016 accounted for $70 \%$ of the total death toll of flood disasters in that year. Flash flood disasters occur widely and frequently in China. Due to their unexpectedness, it is difficult to predict and prevent them. The flash flood disasters in China form rapidly with great destruction and have their seasonal and regional features (Zhang, 2016; Ren H Y, 2007; Gang, 2016).

To understand the basic situation of flash flood disaster prevention areas, China defines the flash flood prevention areas and hazard zones in a scientific way. China has also scientifically determined the early warning indicators for flash flood disasters to improve the monitoring, warning, prevention and control of flash flood disasters. During 2013 to 2016, China carried out a national flash flood disaster investigation and assessment. The investigation and assessment combine census, detailed survey and adopt methods such as interior survey, field measurement and hydrological analysis to provide reliable data support for the disaster warning, forecast and control in flash flood disaster counties (Guo L, 2012).

It is the first time for China to systematically conduct the flash flood disaster investigation and assessment, which involves the work at all levels of the central government, provincial governments, municipal governments, counties, townships to villages. The scale of the flash flood disaster investigation and assessment is unprecedented in China's water conservancy history. The range, population distribution and underlying surface conditions of China's flash flood disaster prevention areas have been basically identified. A national result database is established with the preliminary analysis of the storm flood characteristics in the villages along rivers, the assessment of their current flood control abilities, and the calculation of early warning indicators.

\section{Methodological Framework}

The flash flood disasters investigation and assessment consists of 4 parts:

(1) fundamental work including data processing and base working map drawing;

(2) flash flood disasters investigation $(Z, 2015)$ which is mainly conducted with interior and exterior methods to get the necessary information on the flash flood disaster prevention areas such as spatial distribution, population distribution, economic development, historical flood disasters, water conservancy projects, and monitoring and early warning facilities/equipment;

(3) flash flood disaster analysis and assessment (Guo, 2017; Yao, 2016), which is mainly based on the survey results to carry out the analysis of storm flood law in small river basins, the analysis of stagedischarge relation and the analysis of population and elevation, and to assess the current flood control abilities of the villages along rivers, and to identify the range of hazard zones, the transfer routes and the temporary settlements;

(4) review and summary of flash flood disaster investigation and assessment results, which focuses on the review of data integrity, standardization, rationality which should be conducted level by level according to the order of county-municipality/province-central government. 


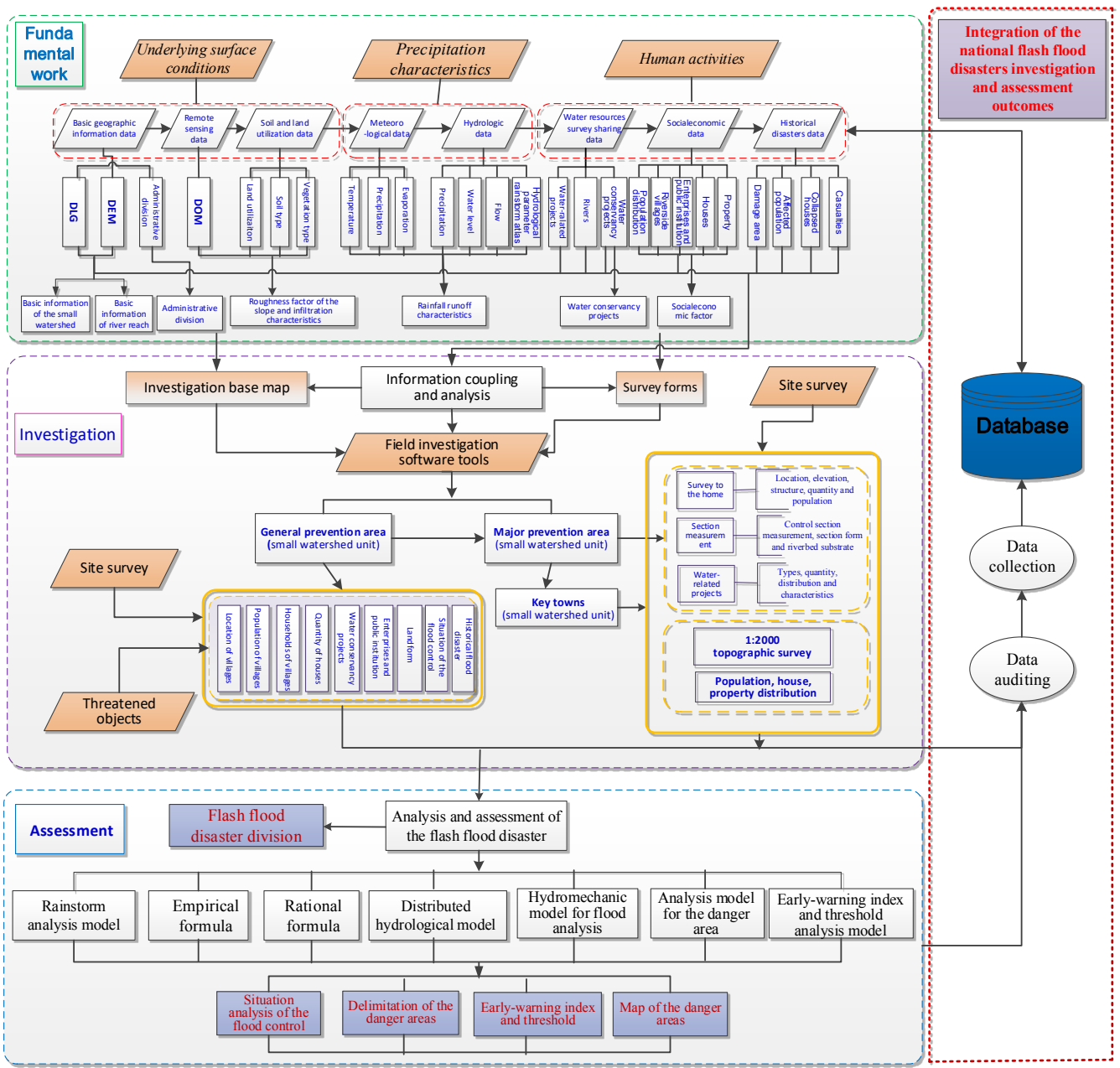

Figure 1: Technical roadmap of National flash flood disasters investigation and assessment

\section{Results and Discussion}

\subsection{Results}

A total of 2,040,000 villages, 32,000 towns and 2,138 county-level divisions are surveyed in this investigation, which covers a land area of 7,550,000 $\mathrm{km}^{2}$ and a population of 890 million. Through this investigation, the range, population distribution, socioeconomic conditions and historical flash flood disasters of China's flash flood prevention areas have been primarily identified. Essential characteristics and storm flood characteristics of 530,000 small river basins have also been found out. Then some investigation and assessment result data sets are established. 


\begin{tabular}{|c|c|c|}
\hline No. & Result & Result Description \\
\hline 1 & Spatial Information Database & $\begin{array}{l}52 \text { layers, } 45,760,000 \text { objects; satellite remote sensing } \\
\text { images across China ( } 2.5 \text {-meter resolution), 56TB. }\end{array}$ \\
\hline 2 & Attribute Database & $\begin{array}{l}58 \text { attribute tables, } 54,855,495 \text { data records; } 14 \text { types of } \\
\text { multimedia data, a total of } 11,230,000 \text { multimedia files; } 7 \\
\text { types of document, a total of } 335,000 \text { documental files; } \\
\text { 23TB of data. }\end{array}$ \\
\hline 3 & $\begin{array}{l}\text { Provincial Level Base } \\
\text { Working Map }\end{array}$ & 30 provinces, a total of 26409 maps of $1: 50,000,8.6 \mathrm{~TB}$. \\
\hline 4 & $\begin{array}{l}\text { County Level Base Working } \\
\text { Map }\end{array}$ & Base working map data of 2138 counties, $13.5 \mathrm{~TB}$. \\
\hline 5 & $\begin{array}{l}\text { Basic Information Data Set } \\
\text { of Small River Basins in } \\
\text { Mountainous Areas of China }\end{array}$ & $\begin{array}{l}530,000 \text { small river basins; } 16 \text { layers; } 75 \text { critical } \\
\text { attributes and hydrological characteristics, topological } \\
\text { relations, standardized unit hydrographs, 1.6TB. }\end{array}$ \\
\hline 6 & $\begin{array}{l}\text { Supplementary Data Set for } \\
\text { Administrative Divisions of } \\
\text { Flash Flood Prevention in China } \\
\text { ( Township and Village Levels) }\end{array}$ & $\begin{array}{c}\text { Township data results, including a real data from } 2881 \\
\text { counties in } 31 \text { provinces and point data from 2,040,000 } \\
\text { villages. }\end{array}$ \\
\hline 7 & $\begin{array}{l}\text { Data Set of National Land } \\
\text { Use and Vegetation Types }\end{array}$ & $\begin{array}{c}\text { Data of national land use and vegetation types ( } 30 \mathrm{~m} \text { and } \\
2.5 \mathrm{~m} \text { resolutions), } 206 \mathrm{~GB} \text {. }\end{array}$ \\
\hline 8 & $\begin{array}{l}\text { Data Set of National Soil } \\
\text { Types and Soil Texture Types }\end{array}$ & $\begin{array}{l}\text { Data of national soil types and soil texture types, } \\
261.68 \mathrm{MB} \text {. }\end{array}$ \\
\hline
\end{tabular}

Table 1: National flash flood disasters investigation and assessment results

\subsection{Discussion}

\subsubsection{Distribution Pattern of Flash Flood Disaster Prevention Areas}

Based on the upstream and downstream relation, village distribution and population distribution, the range of national flash flood prevention areas has been preliminarily defined by taking a small river basin where a key flash flood prevention village or a general flash flood prevention village is located as a basic unit. Each flash flood prevention area has also been preliminarily divided into several zones based on its area.

The red area represents the key prevention area severely threatened by the flash flood disaster and the earthy yellow area represents the general prevention area threatened by the flash flood disaster. According to the investigation results, the national prevention area covers 3.86 million $\mathrm{km}^{2}$, accounting for $40 \%$ of the national territorial area. From the provincial aspect, Sichuan and Yunnan cover the most of the prevention area, $369000 \mathrm{~km}^{2}$ and $344000 \mathrm{~km}^{2}$, respectively, and their proportions in the countylevel prevention area are $73 \%$ and $89 \%$, respectively. These areas are high incidence areas and susceptible areas of the flash flood disasters (Liu, 2011), affecting by such multiple factors as topography, landform, geologic structure, rainfall and earthquake while the population density there is large. The general prevention area is 2.66 million $\mathrm{km}^{2}$ and the key prevention area is 1.20 million $\mathrm{km}^{2}$, concentrating the distribution in Qinghai-Tibet Plateau-Sichuan Basin transitional zone, SichuanYunnan border land, the North China, Hengduan Mountainous Region, Loess Plateau and the eastern coastal regions, mainly involving provinces including Sichuan, Yunnan, Gansu, Shaanxi, Hebei, Hunan, Henan, Shanxi, Fujian and Guangdong. 


\subsubsection{Population Distribution Law of Flash Flood Disaster Prevention Areas}

Through the flash flood disaster investigation, the distribution of 2,040,000 natural villages within the national flash flood disaster prevention areas has been preliminarily identified. Then based on village location, historical losses caused by flash flood disasters and storm flood characteristics [10, 11], general disaster prevention villages, key disaster prevention villages and hazard zones are defined. The population, number of families and number of houses threatened by flash flood disasters are collected through household surveys. The population threatened by flash flood disasters is counted and classified by taking a small river basin as a unit. Based on the population distribution, disaster prevention areas are classified into 4 levels.

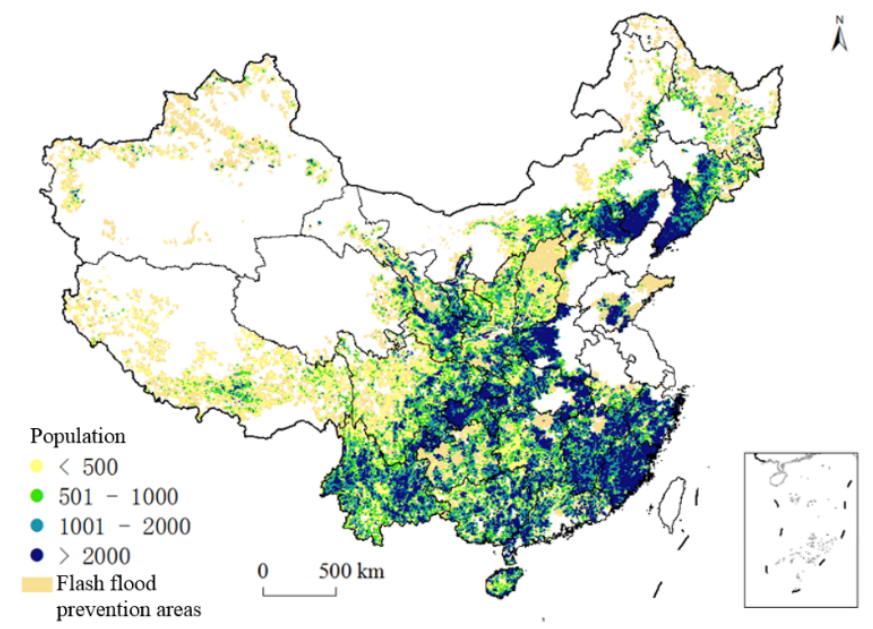

Figure 2: Spatial distribution of human population in national flash flood disasters prevention areas

The deep blue dots represent the population threatened by the flash flood disasters in the small watershed is 2000 and above and the light blue dots, green dots and yellow dots represent the population is 1000-2000, 500-100 and lower than 500, respectively. Reflecting the population aggregation, the spatial distribution of population indicates that the population threatened by the flash flood disasters mainly spreads over the North China and Central China Plains and Sichuan Basin, including such provinces as Fujian, Henan, Hebei, Shandong, Shanxi, Jiangxi, Sichuan, Zhejiang, Gansu and Liaoning. The higher the urbanization degree is, the greater the losses caused by the flash flood will be (Li C Z, 2012). Therefore, the flash flood disaster prevention in China should focus on strengthening the earlywarning capacity building in the hilly areas with dense population.

\subsubsection{Spatial and Temporal Distribution Law of Historical Flash Flood Disasters}

In this large-scale investigation, the flash flood disasters occurring in China during 1950 to 2016 are surveyed in details. Based on the statistical analysis of time, death toll and scale, a temporal sequence relation map of past flash flood disasters is drawn. The analysis results show that for the past 60 years, since the founding of the People's Republic of China, the frequency of flash flood disasters in China has increased year by year due to the effect of extreme weather events. However, the frequency of flash flood disasters with casualties shows a downward trend. The investigation and spatial distribution law 
of historical flash flood disasters show that China's flash flood disasters are characterized by their wide distribution and high frequency. Flash flood disasters in China also have their regional features. The typical flash flood events occurring in recent years, such as Typhoon Bilis in 2006 which caused a large area of flash flood disaster in Hunan Province, sufficiently demonstrate that it is essential to explore the storm flood law in the regions without data and identify the potential relation between underlying surface characteristics and disaster occurrence in the mountainous areas of China.

Since the founding of the P.R.C., the frequency of occurrence of the flash flood in China increased from 135 at the beginning to 1813 by now, influenced by extreme weather-climate events. However, the flash flood disasters with casualties declined. As shown in Figure 3 the flash flood with casualties/total number decreased from $40 \%$ at the beginning of the founding and it was $12 \%$ in 2000 2010 and reduced to $6 \%$ from 2010 . This indicates that the engineering and non-engineering measures for the flash flood disasters prevention have produced the significant results[3], and therefore, the dealth toll decreased year by year and the disaster prevention capabilities in the hilly regions are strengthened gradually. From the spatial distribution of the historical flash flood disaster (Figure 4), the flash flood disasters were mainly distributed in Qinghai-Tibet Plateau-Sichuan Basin transitional zone, SichuanYunnan border land, Loess Plateau, Qinling-Daba mountainous regions, the Southwest Guizhou region, the eastern coastal regions and the North China and Central China, which indicates that the peculiar topography and landform are key reasons causing the flash flood. Besides, the disasters with casualties mainly occurred in Sichuan, Yunnan, Chongqing, Gansu, Ningxia, Shaanxi, Guizhou, Henan, Hunan, Shanxi, Guangxi, Fujian and Guangdong, which are featured by complex landform and large population density, especially the higher urbanization. This shows that the factor of the population distribution needs to be fully considered in the division of the flash flood disaster prevention areas. To sum up, it can be learnt from the investigation of the historical flash flood disasters and the spatial distribution pattern, the flash flood disasters in China possess the features of wide distribution and frequent and regional occurrence. The recent typical flash flood disasters, such as the large-area of flash flood disaster in Hunan in 2006 caused by Bilis, the debris flow disaster in Zhouqu, Gansu in 2010, the debris flow disaster in Taining, Fujian in 2016 and the debris flow disaster in Liangshan, Sichuan in 2017, have shown clearly that it is significantly to explore the rainfall and flood rules in un-gauged regions and establish the potential relationship between the underlying surface features of the hilly regions and the disaster occurrence.

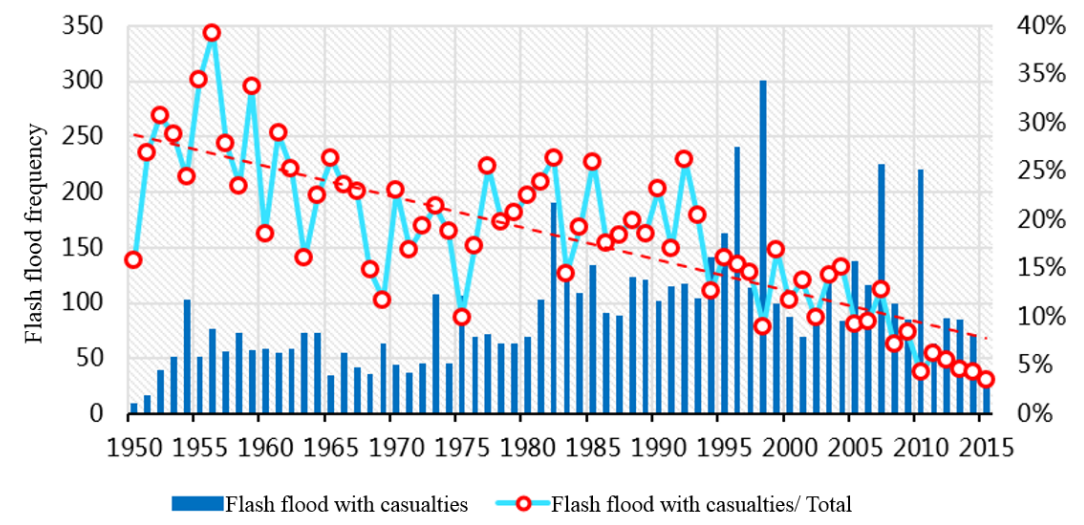

Figure 3: Historical flash flood disasters situations in China

\subsubsection{Analysis of Early Warning Abilities}

According to the analysis and assessment results of the villages along the rivers within the national flash flood disaster prevention areas, the designed rainfalls for 530,000 small river basins are obtained. The designed flood indicators, critical rainfall indicators as well as early warning indicators are 
established for 170,000 villages along rivers. The flash flood disaster possibility is closely related to critical rainfall as it triggers flash flood disasters. Given China's vast territory and big rainfall difference, a coefficient $\mathrm{K}$ of critical rainfall/designed rainfall ratio is used in this study as an indicator to represent the flash flood warning ability and hazard level. The smaller the ratio is, the lower the threshold rainfall is and the higher the frequency of flash flood disasters is.

$$
K=\frac{\operatorname{Rainfall}_{T}}{\operatorname{Rainfall}_{D}}
$$

Rainfall $_{T}$ is threshold rainfall, Rainfall R $_{\text {is the designed rainfall. }}$

In the figure 5, the value of $\mathrm{k}$ of the yellow dot is less than 1 , which indicates that the threshold of disaster outbreak is relatively low and the disaster is likely to occur, therefore, timely warning is needed. The village shown as the green dot is located in the flash flood disaster area with general possibility and the village shown as the blue dot is in the area with lower possibility. As shown in Figure 5, the area with possible flood disaster is mainly distributed in Sichuan Basin, Sichuan-Yunnan border land, Qinling-Daba mountainous regions, the Southwest Guizhou region, the southeast coast areas and the North China regions, especially in such provinces as Sichuan, Yunnan, Guizhou, Chongqing, Hunan, Guandong, Fujian, Jiangxi, Shanxi, Shaanxi, Gansu and Hebei, with Hu's Line as the geographical boundary. These regions possess the features of complex and diverse geological conditions, large multiyear average rainfall and easy occurrence of flash flood and geological disasters.

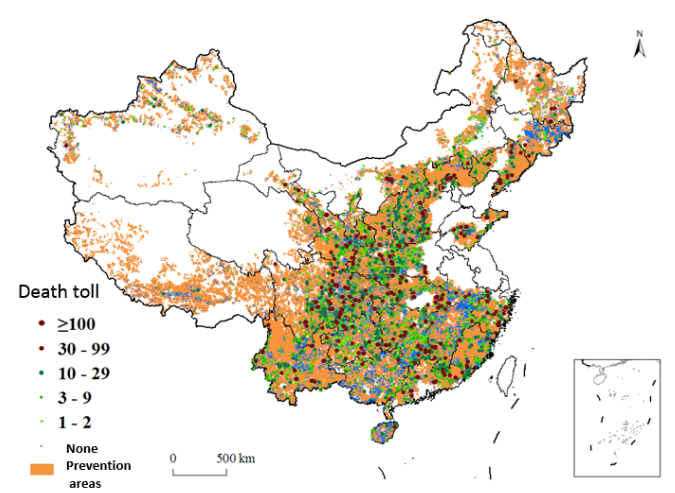

Figure 4: Historical flash flood disasters distribution situation in China

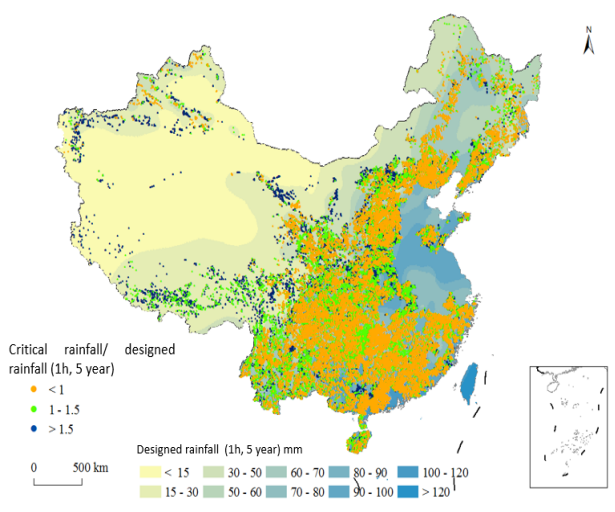

Figure 5: Distribution of flash flood warning threshold in China

\section{Conclusions}

After four years of flash flood disaster investigation and assessment, the range and population distribution of flash flood prevention areas in China have been preliminarily defined. The primary information of flash flood prevention areas such as hydrology, topography and socioeconomic conditions is obtained. Then a national primary database is established and a national base working map is drawn to divide these areas into small river basins and comprehensively analyze the essential attributes and runoff yield and concentration characteristics for such small river basins. Fruitful results have been made with the application software developed for this field. A preliminary discussion on the spatial distribution law of flash flood disaster elements is also made in the paper. 
Flash flood disaster assessment lays the basis of disaster prevention work. Fruitful results have been made in this flash flood disaster assessment and they have a full application prospect. Therefore, in the subsequent flash flood disaster prevention work, China needs to enhance the use and exploration of existing investigation and assessment results, and expand the data application scope and fields. In this way, China's emergency rescue abilities level of flood control and disaster reduction in case of a disaster can be overall improved to provide a sturdy data support and decision-making basis for industry policies.

\section{References}

Gang, Z. B. (2016). Assessment on the hazard of flash flood disasters in china. Journal of Hydraulic Engineering, 47, pp. 1133-1142.

Guo L, Liu. C J. (2012). Working plan for mountain flood investigation and evaluation in China. China Water Resources, 23, pp. 10-12.

Guo, L. Z. (2017). Achievements and preliminary analysis on china national flash flood disasters investigation and evaluation. Journal of Geo-Information Science, 19, pp. 1548-1556.

Keefer, D. K. (1987). Real-time landslide warning during heavy rainfall. Science, 238, pp. 921-925.

Li C Z, S. D. (2012). Method of flash flood disaster warning index. China Water Resources, 9, pp. 5456.

Liu, J. H. (2011). A comprehensive study on precipitation change over monsoon marginal areas during last five centuries. Scientia Geographica Sinica, 31, pp. 401-407.

Ren H Y, Z. X. (2007). Causes of Flash flood disasters in China. China Water Resources, 14, pp. 1820.

Shang Q M, H. X. (2007). eople oriented idea of flash flood disaster prevention. Yangtze River, 38, pp. 6-8.

Yao, Q. X. (2016). Analysis and evaluation of flash flood disasters: a case of lingbao county of henan province in china. Procedia Engineering, 154, pp. 835-843.

Z, H. Y. (2015). Q \& A in key technical issues of on-site investigation in flash flood impact analysis. China Flood and Drought Management, 2, pp. 26-33.

Zhang, Z. (2016). Mountain torrent disaster prevention and control measures and their effects. Water Resources \& Hydropower Engineering, 47, pp. 1-5. 